\section{Impairment of Motivational Efforts: Another Complication of Opioid Compromise of Sleep Quality?}

To the Editor:

Fitzcharles and Shir ${ }^{1}$ emphasize the "negative effects of opioids in chronic pain conditions." Kim, et $a l^{2}$ attribute detrimental effects of opioids to compromise of adherence to therapeutic regimens, but Fitzcharles and Shir ${ }^{1}$ suggest an important role for other factors, including substance or psychoactive drug use, and disease duration and severity as compromising therapeutic responsiveness. Kim, et $a l^{2}$ suggest that opioids compromise motivation (suggesting a relationship to cannabinoid induction of "amotivational" disorders) and enhance fatigue. These may certainly be factors in the final common pathway of opioid interference and physiologic compromise, but a simpler primary factor may be even more significant in patients with fibromyalgia (FM).

If loss of motivation is also a manifestation of the mental "dulling" characteristic of opioid usage, perhaps there is another operative factor. One of the major characteristics of FM is sleep compromise $e^{3,4,5,6}$. Indeed, restoring stage IV/ rapid eye movement sleep appears to mollify that disorder ${ }^{6,7,8}$. Because opioids interfere with reaching those sleep states ${ }^{3,9,10}$, is it any surprise that they are not only ineffective in treating FM, but that they actually compromise the benefit of any other interventions?

BRUCE M. ROTHSCHILD, MD, West Virginia University School of Medicine, Morgantown, West Virginia, and Carnegie Museum, Pittsburgh, Pennsylvania, USA. Address correspondence to Dr. B.M. Rothschild, West Virginia University School of Medicine, Morgantown, West Virginia 26506, USA. E-mail: spondylair@gmail.com

\section{REFERENCES}

1. Fitzcharles MA, Shir Y. Another nasty effect of opioids: attenuating the benefits of motivational interviewing in fibromyalgia? (editorial) J Rheumatol 2017;44:407-9.

2. Kim S, Slaven JE, Ang DC. Sustained benefits of exercise-based motivational interviewing, but only among nonusers of opioids in patients with fibromyalgia. J Rheumatol 2017;44:505-11.

3. Rothschild BM. Zolpidem efficacy in fibromyalgia. J Rheumatol 1997;24:1012-13.

4. Mork PJ, Nilsen TI. Sleep problems and risk of fibromyalgia: longitudinal data on an adult female population in Norway. Arthritis Rheum 2012;64:281-4.

5. Thomas RJ. Sleep as a window into the world of fibromyalgia syndrome. J Rheumatol 2011;38:2499-500.

6. Rothschild BM, Vu J. Retrospective assessment of fibromyalgia therapeusis. Compr Ther 1994;20:545-9.

7. Walsh JK, Erman M, Erwin CW, Jamieson A, Mahowald M, Regestein Q. Subjective hypnotic efficacy of trazodone and zolpidem in DSMIII-R primary insomnia. Hum Psychopharmacol Clin Exp 1998;13:191-8.

8. Davies KA, Macfarlane GJ, Nicholl BI, Dickens C, Morriss R, Ray $\mathrm{D}$, et al. Restorative sleep predicts the resolution of chronic widespread pain: results from the EPIFUND study. Rheumatology 2008;47:1809-13.

9. Rothschild BM. To sleep, perchance to dream: restoration of normal sleep physiology versus sedation in management of sleep disorders and fibromyalgia. Rheumatologist 2015;9:67.

10. Pandharipande PP, Pun T, Herr SA, Maze M, Girard TD, Miller RR, et al. Effect of sedation with dexmedetomidine vs lorazepam on acute brain dysfunction in mechanically ventilated patients: The MENDS randomized controlled trial. JAMA 2007;298:2644-53.

J Rheumatol 2018;45:7; doi:10.3899/jrheum.170507 